Research Article

\title{
Study of the Mechanism of Fracture Grouting in Deeply Buried Rock Strata Based on Bingham Fluid Slurry
}

\author{
Xiangyang Liu, ${ }^{1}$ Hua Cheng $\mathbb{D}^{1,2}$ Jian Lin, ${ }^{2}$ Chuanxin Rong, ${ }^{2}$ Mingjing Li, $^{2}$ and \\ Huidong $\mathrm{Xu}^{3}$ \\ ${ }^{1}$ School of Civil and Hydraulic Engineering, Hefei University of Technology, Hefei 230000, China \\ ${ }^{2}$ School of Civil Engineering and Architecture, Anhui University of Science and Technology, Huainan 232001, China \\ ${ }^{3}$ China Coal Mine Construction Group Corporation Ltd., Hefei 230000, China \\ Correspondence should be addressed to Hua Cheng; hcheng@aust.edu.cn
}

Received 7 August 2019; Accepted 16 November 2019; Published 7 December 2019

Academic Editor: Hui Yao

Copyright (C) 2019 Xiangyang Liu et al. This is an open access article distributed under the Creative Commons Attribution License, which permits unrestricted use, distribution, and reproduction in any medium, provided the original work is properly cited.

\begin{abstract}
In view of the fact that the theory of fracture grouting in deeply buried rock strata seriously lags behind engineering practices, a circular fracturing diffusion model of a single fracture was established by considering numerous influencing factors of deeply buried rock strata, such as the crustal stress characteristics, rock mechanical properties, and time-varying characteristics of the serous viscosity. By setting the stress intensity factor $K_{\mathrm{I}}$ equal to the material fracture toughness $K_{\mathrm{IC}}$ at the fracture tip as the criterion for fracturing, the diffusion equation for the fracture grouting was derived and verified experimentally. Theoretical analysis shows that the fracture grouting pressure $P_{0}$ is linearly proportional to the depth of the strata $H$ and the lateral pressure coefficient $k$. The time-varying characteristics of the serous viscosity have an important influence on the grouting pressure and the diffusion radius. Its early impact is small, while its later impact is large. The diffusion radius of the grouting is indirectly proportional to the grouting pressure and the grouting flow rate. In order to increase the diffusion radius of the grouting, the grouting pressure and the grouting flow rate should be increased simultaneously. In order, the main factors influencing the diffusion radius of the fracture grouting are the time-varying characteristics of the serous viscosity, the grouting pressure, the grouting flow rate, and the depth of the strata.
\end{abstract}

\section{Introduction}

Strata grouting is one of the indispensable technologies for preventing water disasters and strengthening soft ground in underground engineering projects [1]. Recently, due to the increase in the depth of mining exploitation in China, more and more projects have used grouting technology to prevent water disasters in deeply buried rock strata. For example, in the ground pregrouting of bedrock in deep mine shafts (400 $\mathrm{m}$ deep), grouting is applied to the aquifers at the top and bottom of the coal mining working face to prevent water flow, etc. [2].

Because deep strata are characterized by large ground pressure, high water pressure, and generally poor injectability [3], most strata require the use of high-pressure fracture grouting to achieve a better grouting effect. Strata grouting is related to the geological environment, grouting technology, grouting materials, and the grouting process, besides the uncertainty in the distribution of the pores, fractures, bedding, and joints of the rock strata. The use of grouting in engineering projects has seriously lagged behind its need, and thus, grouting engineering designs lack scientific theoretical guidance and are still based on engineering analogy, although domestic and foreign experts and scholars have carried out a great deal of research on the theory of fracture grouting.

At present, few theoretical studies have been conducted on the diffusion process of fracture grouting. Gustafson et al. [4] established the grout migration equation for a single fracture under constant pressure grouting based on the Bingham fluid constitutive model. Houlsby [5] conducted a single-fracture grouting simulation test and tested the 
grouting pressure, flow rate, and other grouting parameters. Lombardi [6] and Baker [7] deduced the maximum diffusion radius of a Bingham fluid and a Newtonian fluid in rock mass fractures, respectively. Chen et al. [8] simulated the fracture grouting diffusion process using the finite element method (FEM) and volume of fluid (VOF) method. Zou et al. [9] and Wittlke [10] also proposed similar theories on this problem. In China, Zou et al. [11], Sun et al. [12, 13], and Zhang and Zou [14] studied the laws of Newtonian fluid, Bingham fluid, and power-law fluid fracture grouting, respectively. They obtained the equation relating the grouting pressure and fracture diffusion radius and carried out the verification and analysis using simulation experiments of fracture grouting. Zhang et al. [15] discussed the diffusion mechanism of a Herschel-Bulkley fluid under the influence of gravity, fracture inclination, and other factors. Shu-cai et al. [16-19] established the grout migration equation for a single fracture on the condition of time-varying serous viscosity based on previous studies.

The above research on the continued splitting and cracking of fracture is based on the assumption that the slurry pressure at the tip of the fracture is equal to the minimum principal stress [20], ignoring the influence of the fracture geometry on the split propagation, and not considering the coupling effect of the slurry flow and the fracture wall. In particular, for complex geological conditions, natural primary fractures randomly distributed throughout a space are affected by the internal slurry pressure and the external crustal stress. In addition, the fracturing and expansion of these fractures are affected by many natural factors. According to the principle of hydraulic fracturing, the stress intensity factor at the fracture tip increases under high hydraulic pressure, which promotes fracture initiation and expansion. Compared with hydraulic fracturing, the essential differences in fracture grouting are that the slurry has a greater viscosity relative to the water and the viscosity increases with time, which hinders the fracturing and expansion behavior of the slurry. Therefore, based on the fracture mechanics theory and fluid mechanics, in this study, we investigate the fracture diffusion mechanism of viscoelastic grout with time-varying characteristics in deeply buried rock strata and establish a theoretical single-fracture grouting model, in which the stress intensity factor $K_{\mathrm{I}}$ is equal to the material fracture toughness $K_{\mathrm{IC}}$ at the fracture tip. In addition, we present a diffusion equation of fracture grouting, which takes into consideration the formation factors and time-varying characteristics of viscosity. Finally, we analyze the influences of the crustal stress, grouting pressure, grouting flow rate, and time-varying characteristics of the serous viscosity on the grout fracture diffusion, which provides a theoretical basis for grouting design and the optimization of deeply buried rock engineering.

\section{Circular Fracture Diffusion Model of a Single Fracture}

2.1. Basic Assumptions. For the mathematical formulation, make the following assumptions:
(1) The slurry is an anisotropic incompressible Bingham fluid, and the injected rock mass is an isotropic elastomer.

(2) Except for near the grouting hole, the slurry flow is laminar. There is no slip at the crack boundary, and the slurry movement velocity at the boundary of the fracture channel is 0 .

(3) The forces at the fracture tip and the upper and lower side walls of the fracture channel are perpendicular to the axis of symmetry of the fracture channel.

(4) The slurry only exists in the fracture channel, and its quality is not lost with the flow.

2.2. Circular Fracture Diffusion Model of a Single Fracture. Due to the large number of joints, fractures, and bedding structures naturally distributed in rock strata, it is necessary to analyze the mechanism of single-fracture grouting considering crustal stress when studying the diffusion law of fracture grouting in deeply buried rock strata. As shown in Figure 1(a), we assume that the maximum principal stress and the minimum principal stress within the rock strata are in the horizontal and vertical directions, respectively. The horizontal and vertical stresses on a single fracture are $\sigma_{1}$ and $\sigma_{3}$, respectively. The angle between the fracture surface and the maximum principal stress is $\alpha$ when the grouting pressure $P_{\mathrm{s}}$ in the fracture is stable. Based on fracture mechanics theory, when $\alpha=0$ and the internal pressure $P_{\mathrm{s}}$ reaches $K_{\mathrm{IC}} / \sqrt{\pi L}+\sigma_{3}$, the fracture in the rock strata fractures and expands. In fracture grouting, when the grouting fluid flow is shear flow, the grouting pressure in the fracture channel exhibits a decreasing nonuniform load distribution, as shown in Figure 1(c). In particular, there are natural fractures in deeply buried rock strata, and their angular $(\alpha)$ positions are randomly distributed. Therefore, during fracture grouting, the fracturing of the fracture is caused by the grouting pressure throughout the entire inner fracture. The criterion should be that the grouting pressure on the inner wall of the entire fracture and the crustal stress on the outer wall at the fracture's tip generate a stress intensity factor $K_{\mathrm{I}}$ equal to the material fracture toughness $K_{\mathrm{IC}}$. Based on the above analysis, a circular fracture diffusion model for a single fracture was established, as shown in Figure 1(b).

\section{Grouting Fracturing Pressure and Fracture Channel Expansion Conditions}

3.1. Determination of the Grouting Fracture Pressure. Assuming that the injected rock mass has no natural defect, such as joint and fracture, the stress on the grouting hole is shown in Figure 2. The radius of the bare hole section of the grouting hole is $r$, the grouting pressure is $P_{0}$, the maximum principal stress is $\sigma_{1}$, and the minimum principal stress is $\sigma_{3}$. According to the hydraulic fracturing principle [21], in the case of no liquid filtration loss, the grouting pressure in a horizontal fracture is

$$
P_{0}=\frac{\sigma_{3}+\sigma_{t}}{0.94},
$$




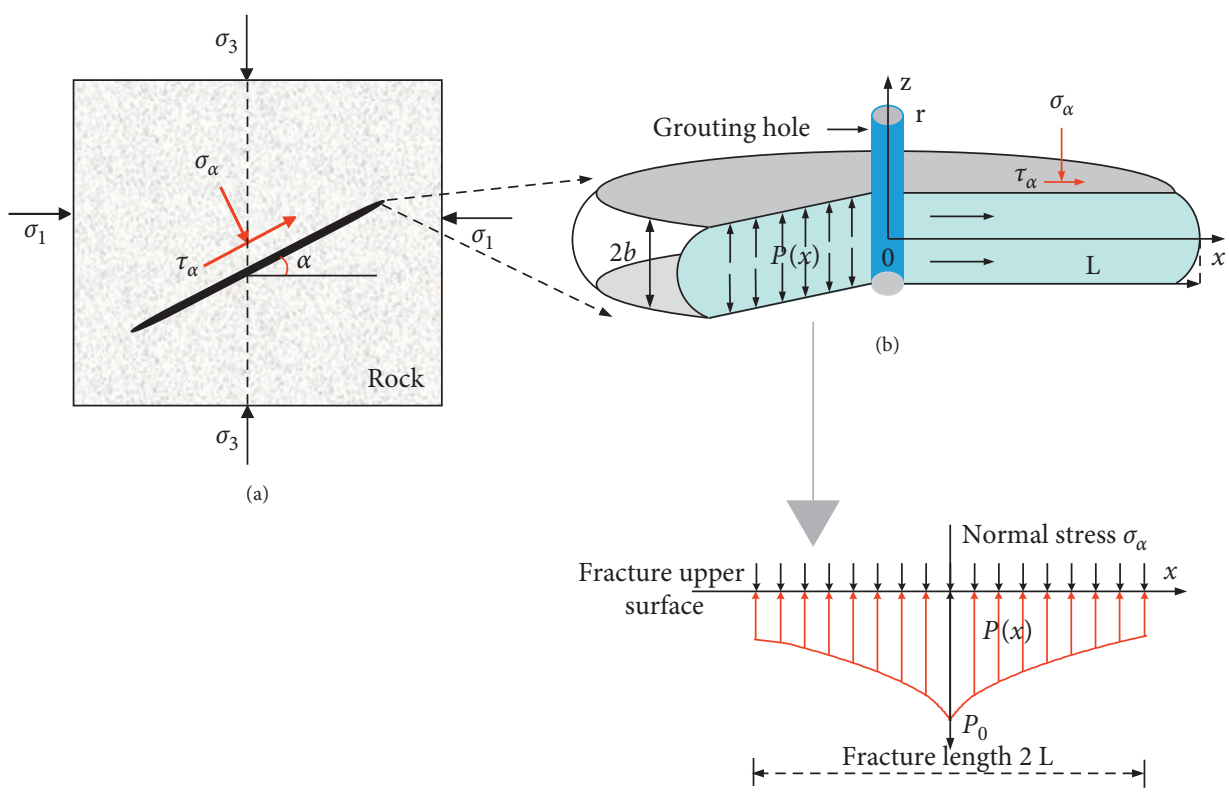

(c)

FIGURE 1: Force diagram of a fracture. (a) Single-fracture stress. (b) Fracturing diffusion model of single fracture. (c) Pressure distribution in fracture. $\sigma_{\alpha}$ is the normal stress on the fracture's surface; $\tau_{\alpha}$ is the shear stress on the fracture's surface; $r$ is the radius of the grouting hole; $2 b$ is the height of the fracture channel; $L$ is the fracture length; and $w(x)$ corresponds to the fracture width at different values of $x$.



FIGURE 2: Force diagram of a bare hole during fracture grouting.

where $\sigma_{\mathrm{t}}$ is the tensile strength of the rock.

According to the test results reported in reference [22], the tensile strength obtained using the pore compression fracturing method is approximately 2.5 times the pure tensile strength obtained using the uniaxial direct tensile method under triaxial pore pressure. This leads to the following relationship:

$$
\sigma_{\mathrm{t}}=2.5 \sigma_{\mathrm{t}}^{*},
$$

where $\sigma_{\mathrm{t}}$ is the tensile strength determined using the pore pressure fracturing method for rock and $\sigma_{\mathrm{t}}^{*}$ is the uniaxial tensile strength of the rock.
3.2. Criterion for Fracturing and Expansion. Fracture grouting is a process in which the rock mass fractures expand successively under the action of high grouting pressure and then they open further after the fractures connect with each other. According to the fracture propagation theory of hydraulic fracturing $[23,24]$, when the pressure within the fracture is distributed continuously along the entire length of the fracture, the stress intensity factor $K_{\mathrm{I}}$ at the fracture's tip is

$$
K_{\mathrm{I}}=\frac{2}{\sqrt{\pi L}} \int_{r}^{L} \frac{\Delta P(x)}{\sqrt{L^{2}-x^{2}}} x \mathrm{~d} x,
$$

where $\Delta P(x)=p(x) \sigma_{\alpha}$ is the net pressure within the fracture, $P(x)$ is the fluid pressure with the fracture and $P(L) \geq 0, \sigma_{\alpha}$ is the crustal stress perpendicular to the fracture's surface, $r$ is the radius of the grouting hole, and $L$ is the fracture length.

For the expansion distance, the radius of the grouting hole is small. Therefore, the parameter $r$ in equation (3) can be ignored, and the stress intensity factor $K_{\mathrm{I}}$ at the fracture tip is

$$
K_{\mathrm{I}}=\frac{2}{\sqrt{\pi L}} \int_{0}^{L} \frac{\Delta P(x)}{\sqrt{L^{2}-x^{2}}} x \mathrm{~d} x .
$$

In engineering, the fracture propagation condition is of the greatest concern. According to fracture mechanics [23], the form is 


$$
\begin{aligned}
K_{\mathrm{I}} & =K_{\mathrm{IC}}, \\
K_{\mathrm{IC}} & =\sqrt{\frac{2 E \varepsilon}{1-\chi^{2}}},
\end{aligned}
$$

where $K_{\mathrm{IC}}$ is the material fracture toughness, $E$ is Young's modulus, $\varepsilon$ is Poisson's ratio, and $\chi$ is the specific surface energy.

\section{Bingham Fluid Fracturing Diffusion Equation}

4.1. Slurry Constitutive Equation. The different grouting materials used in engineering can be divided into two categories: Newtonian fluids and Bingham fluids [25]. Cement slurry, cement and sodium silicate slurry, and cementbased speed setting slurry with a water-cement ratio of $W /$ $C=0.6-1$, which are commonly used, are all generalized as Bingham fluids. The most commonly used cement and sodium silicate grout ( $C-S$ grout) materials are used in this study to carry out the relevant theoretical research.

Both theory and practice show that the viscosity of the slurry increases gradually before solidification, and it is timevarying. The viscosity change of the slurry directly affects the diffusion range of the slurry. Generally, the viscosity of the slurry materials increases with increasing time. As was reported by Zhang et al. [17], the rheology of a quick-setting grout can be expressed as a power function:

$$
u(t)=m t^{n} \text {, }
$$

where $m$ is the flow consistency index $m=8.4310^{-4}-1.8610^{-2}$ and $n$ is the flow behavior index $n=2.066-2.649$. For the convenience of calculation, $n=2.5$ is used in the following calculation.

When the grout flow pattern is a generalized Bingham fluid, the yield shear force and the time-varying characteristics of the plastic viscosity property required by the grout movement are taken into consideration. The grout constitutive equation is as follows:

$$
\tau=\tau_{0}+u(t) \dot{\gamma}=\tau_{0}+u(t)\left(\frac{\mathrm{d} v}{\mathrm{~d} z}\right),
$$

where $\tau$ is the shear stress, $\tau_{0}$ is the yield shear force, $u(t)$ is a time-dependent function of the dynamic viscosity, $\dot{\gamma}$ is the velocity gradient, $t$ is the injection time, $v$ is the velocity, and $z$ is the distance perpendicular to the flow direction.

4.2. Slurry Transport Equation. In grouting engineering, the stress on the fracture wall is solved using the single-fracture slurry diffusion model. Generally, due to the small included angle of the fractures, it is assumed that the fracture walls are parallel to each other, and the length of the fracture tips is relatively small compared to the distance of the fracture expansion. Thus, it can be assumed that the fracture walls are parallel to each other, and the slurry moves in a two-dimensional manner (Figure 3). When the fracture length is $L$, the fluid in the fracture moves in the $x$ direction at velocity $v$

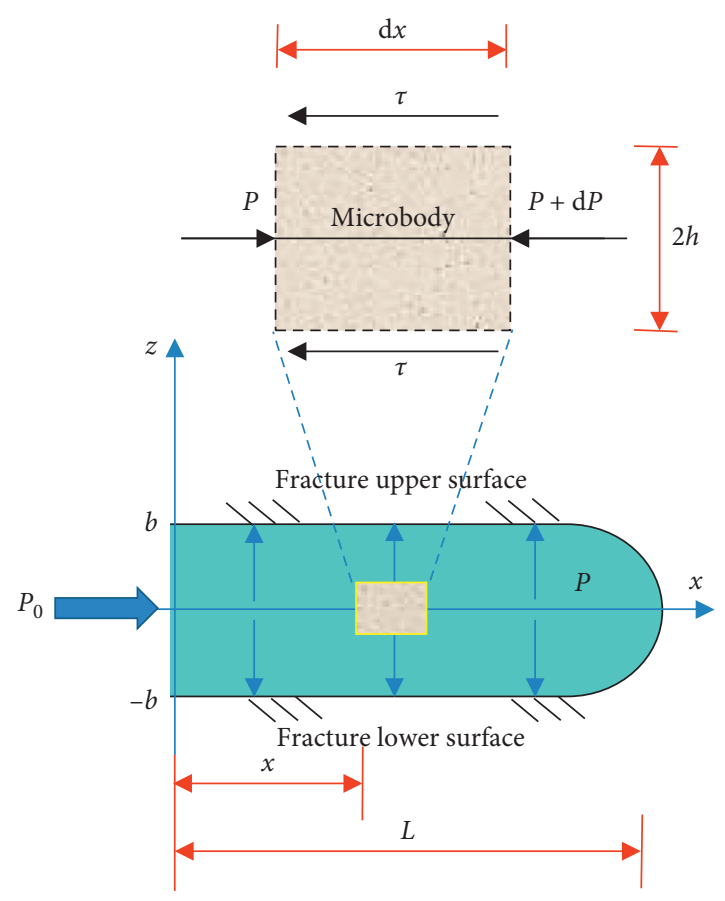

FIGURE 3: Element body equilibrium analysis.

under the grouting pressure. A fluid element within the plane $x \mathrm{o} y$, which is a symmetrical plane of length $\mathrm{d} x$, is shown in Figure 3 . The fluid unit pressure on both ends is $P+\mathrm{d} P$ and $P$, the shear stress on the upper and lower surfaces is $\tau$, and the direction and velocity of the flow are in the opposite direction.

As shown in Figure 3, the equilibrium condition of the stable flow in the coordinate system is [26]

$$
\begin{aligned}
& (P+\mathrm{d} P) \times 2 z(x+\mathrm{d} x) \mathrm{d} \theta-P \times 2 z x \mathrm{~d} \theta+2 \tau x \mathrm{~d} x \mathrm{~d} \theta \\
& -\rho g \times 2 z x \mathrm{~d} x \mathrm{~d} \theta \times \sin \alpha \cos \theta=0,
\end{aligned}
$$

where $\rho$ is the slurry density, $g$ is the acceleration due to gravity, $\mathrm{d} x$ is the length of the element, $\theta$ is the azimuth of the slurry diffusion, $\mathrm{d} \theta$ is the argument of the microunit, $P$ is the slurry pressure, and $\mathrm{d} P$ is the increase in the slurry pressure.

We substitute equation (7) into equation (8) to get

$$
\frac{\mathrm{d} v}{\mathrm{~d} z}=\frac{1}{u(t)} z\left(\frac{\mathrm{d} P}{\mathrm{~d} x}-\frac{3 \tau_{0}}{2 b}-\rho g \sin \alpha \cos \theta\right) \text {. }
$$

When $\tau<\tau_{0}$, there is a central stream nucleus region with a height of $2 h$. That is to say, when $-h \leq z \leq h$, $v=v(z= \pm h), z= \pm b$, and $v=0$. During the grouting process, the grouting pressure gradient is generally much larger than the shear yield stress of the slurry, and the highorder items in the above equation can be ignored. Thus, the average velocity of the slurry on the fracture section can be simplified as

$$
\bar{v}=\frac{-b^{2}}{3 u(t)}\left(\frac{\mathrm{d} P}{\mathrm{~d} x}-\frac{3 \tau_{0}}{2 b}-\rho g \sin \alpha \cos \theta\right),
$$

where $\mathrm{d} P / \mathrm{d} x$ is the pressure gradient along the slurry diffusion direction. 
During the grouting process, according to the law of conservation of mass, the grouting flow rate $q$ is defined as

$$
q=2 \pi x \int_{-b}^{b} \bar{v} \mathrm{~d} z=\frac{-4 \pi x b^{3}}{3 u(t)}\left(\frac{\mathrm{d} P}{\mathrm{~d} x}-\rho g \sin \alpha \cos \theta-\frac{3 \tau_{0}}{2 b}\right) .
$$

Based on equations (6) and (11),

$$
\frac{\mathrm{d} P}{\mathrm{~d} x}=-\frac{3 q m t^{n}}{4 \pi x b^{3}}+\frac{3 \tau_{0}}{2 b}+\rho g \sin \alpha \cos \theta .
$$

If the slurry only flows along the radial direction and the distance of the slurry fracture diffusion at time $t$ is $x$, then $t=4 \pi b x^{2} / q$.

When $x$ is equal to the grouting hole radius $r$ and $P$ is equal to $P_{0}$ of the grouting pressure, the expression of the grouting pressure in the direction of fracture development is as follows [17]:

$$
\begin{aligned}
P(x)= & P_{0}-A\left(x^{2 n}-r^{2 n}\right)+\frac{3 \tau_{0}}{2 b}(x-r) \\
& +\rho g(x-r) \sin \alpha \cos \theta,
\end{aligned}
$$

where $A=(3 m / n) \times 2^{n-3} \times \pi^{n-1} \times b^{n-3} q^{1-n}$ and $P_{0}$ represents the grouting pressure at the grouting hole.

The fracture is subjected to the forces shown in Figure 1(a), according to the rock and soil mechanics, the maximum and minimum principal stresses on the outer wall of the fracture are $\sigma_{1}$ and $\sigma_{3}$, respectively:

$$
\begin{aligned}
& \sigma_{3}=\sigma_{\mathrm{cz}}+P_{\mathrm{S}}, \\
& \sigma_{1}=\sigma_{\mathrm{ch}}+P_{\mathrm{S}}=k \sigma_{\mathrm{cz}}+P_{\mathrm{S}},
\end{aligned}
$$

where $P_{\mathrm{s}}$ is the hydrostatic pressure $(\mathrm{MPa}), P_{\mathrm{S}}=\gamma_{\mathrm{w}} H_{\mathrm{w}}$, and $\sigma_{\mathrm{ch}}$ and $\sigma_{\mathrm{cz}}$ are the vertical effective stress and the lateral effective stress, respectively. $\sigma_{\mathrm{cz}}=\sum_{i=1}^{n} \gamma_{i} H_{i}$, and $k$ is the lateral pressure coefficient. The $k$ value used in this paper is greater than 1, i.e., it mainly studies the case of large horizontal pressure.

The total normal stress applied to the wall of the microfracture $\sigma_{\alpha}(\mathrm{MPa})$ is

$$
\sigma_{\alpha}=\frac{\sigma_{1}+\sigma_{3}}{2}-\frac{\sigma_{1}-\sigma_{3}}{2} \cos 2 \alpha
$$

4.3. Slurry Fracture Diffusion Equation. If the grouting pressure $P_{0}$ is given at the grouting hole, the grouting pressure of the slurry in the fracture channel attenuates due to the action of the grouting shear flow, so the fracture's inner wall bears an uneven distribution load. When the stress intensity factor generated by the grouting pressure within the fracture tip $L$ is less than the material fracture toughness of the rock, as the grouting diffusion range increases, the fracture will no longer fracture and expand.

Substituting equations (13) and (16) into equation (4), we obtain the fracture stress intensity factor:

$$
\begin{aligned}
K_{\mathrm{I}}= & 2 \sqrt{\frac{L}{\pi}}\left[P_{0}+A r^{2 n}-\frac{3 \tau_{0} r}{2 b}-\rho g r \sin \alpha \cos \theta-\sigma_{\alpha}-P_{\mathrm{s}}\right] \\
& -\frac{2 A}{\sqrt{\pi L}} \int_{0}^{L} \frac{x^{2 n+1}}{\sqrt{L^{2}-x^{2}}} \mathrm{~d} x+\frac{2}{\sqrt{\pi L}}\left(\frac{3 \tau_{0}}{2 b}+\rho g \sin \alpha \cos \theta\right)
\end{aligned}
$$$$
\int_{0}^{L} \frac{x^{2}}{\sqrt{L^{2}-x^{2}}} \mathrm{~d} x
$$

If $K_{\mathrm{I}}$ is replaced by $K_{\mathrm{IC}}$, the initial grouting pressure $P_{0}$ with a maximum radius of $L$ can be obtained under the condition of rich water depth and burial:

$$
\begin{aligned}
P_{0}= & \sqrt{\frac{\pi}{4 L}}\left[K_{\mathrm{IC}}+g(L)-\frac{\pi L}{4}\left(\frac{3 \tau_{0}}{2 b}+\rho g \sin \alpha \cos \theta\right)\right] \\
& -A r^{2 n}+\frac{3 \tau_{0} r}{2 b}+\rho g r \sin \alpha \cos \theta+\sigma_{\alpha},
\end{aligned}
$$

where $g(L)=2 A / \sqrt{\pi L} \int_{0}^{L}\left(x^{2 n+1} / \sqrt{L^{2}-x^{2}}\right) \mathrm{d} x$.

According to equation (6), $n=2.066-2.649$. In order to facilitate the discussion of the parameters below, we temporarily set $n=2.5$ and use the trigonometric function of equation (17) to obtain

$$
\begin{aligned}
P_{0}= & \sqrt{\frac{\pi}{4 L}} K_{\mathrm{IC}}+\frac{5 \pi A L^{5}}{16}-\frac{\pi L}{4}\left(\frac{3 \tau_{0}}{2 b}+\rho g \sin \alpha \cos \theta\right) \\
& -A r^{2 n}+\frac{3 \tau_{0} r}{2 b}+\rho g r \sin \alpha \cos \theta+\sigma_{\alpha} .
\end{aligned}
$$

Equations (17) and (18) are the diffusion equations for fracture grouting considering the crustal stress and slurry viscosity. The grouting pressure required for fracturing significantly increases due to the high water and soil pressure. Material fracture toughness $\left(K_{\mathrm{IC}}\right)$, in situ stress $\left(\sigma_{1}\right.$ and $\left.\sigma_{3}\right)$, fracture surface attitude $(\alpha, b)$, grouting pressure $\left(P_{0}\right)$, grouting flow rate $(q)$, and slurry viscosity $(\mu)$ are important factors determining the characteristics of the fracture.

If the time-varying characteristics of the serous viscosity are not taken into consideration, the simplified version of equation (17) can be used to calculate the initial grouting pressure $P_{0}$, which finally makes the slurry fracture and diffuse to the maximum radius $L$ :

$$
\begin{aligned}
P_{0}= & \sqrt{\frac{\pi}{4 L}} K_{\mathrm{IC}}+\frac{3 u_{0} q}{4 L b^{3}} f(L)-\frac{\pi L}{4}\left(\frac{3 \tau_{0}}{2 b}+\rho g \sin \alpha \cos \theta\right) \\
& +r\left(\frac{3 \tau_{0}}{2 b}+\rho g \sin \alpha \cos \theta\right)+\sigma_{\alpha},
\end{aligned}
$$

where $u_{0}$ is the viscosity of the slurry, which is regarded as a fixed value $f(L)=\int_{r}^{L}\left(x \ln ^{x / r}\right) / \sqrt{L^{2}-x^{2}} \mathrm{~d} x$.

When $x \longrightarrow L$, it is known from equation (19) that $f(L)$ has the singularity of the solution, and it can be seen that 
equation (19) also has the singularity of the solution, which obviously does not correspond to the actual situation. In order to avoid the irrational pressure caused by the singularity of the equation, the Taylor series expansion is used to simplify $f(L)$, then (19) can be simplified as

$$
\begin{aligned}
P_{0}= & \sqrt{\frac{\pi}{4 L}} K_{\mathrm{IC}}+\frac{3 u_{0} q}{4 L b^{3}}\left(\left(\frac{\pi}{2}+\frac{2}{3}\right) L+\left(\ln \frac{L}{r}-\frac{3}{2}\right) L \cos \frac{r}{L}\right) \\
& -\frac{\pi L}{4}\left(\frac{3 \tau_{0}}{2 b}+\rho g \sin \alpha \cos \theta\right) \\
& +r\left(\frac{3 \tau_{0}}{2 b}+\rho g \sin \alpha \cos \theta\right)+\sigma_{\alpha} .
\end{aligned}
$$

4.4. Experimental Verification. We verified the correctness of the theoretical derivation using the experimental data of Li [17].

4.4.1. Test Configuration and Design. Ning et al. [27] tested the mechanical parameters of sand conglomerate. Then, they carried out a simulation experiment on fracturing expansion using a large true triaxial fracturing model of sand conglomerate reservoir water (gel fracturing fluid). The test rock sample was a standard cube with a side length of $300 \mathrm{~mm}$, and a blind hole with a diameter of $16 \mathrm{~mm}$ and a depth of $165 \mathrm{~mm}$ was drilled in the center of one side. A steel pipe (shaft) with an outer diameter of $15 \mathrm{~mm}$, an inner diameter of $8 \mathrm{~mm}$, and a length of $135 \mathrm{~mm}$ was mounted in the blind hole using a high-strength epoxy resin adhesive with a $30 \mathrm{~mm}$ open hole section reserved at the bottom.

In order to simulate an underground triaxial stress environment, the triaxial hydraulic loading mode is adopted to apply triaxial stress in the $X, Y$, and $Z$ directions, i.e., $\sigma_{\mathrm{V}}=20 \mathrm{MPa}, \sigma_{\mathrm{H}}=15 \mathrm{MPa}$, and $\sigma_{\mathrm{h}}=5 \mathrm{MPa}$, respectively. Both the direction of the wellbore and the direction of the horizontal minimum principal stress are along the $X$-axis. The radius $(r)$ of the grouting hole is 0.008 metre, the slurry viscosity $\left(u_{0}\right)$ of gel fracturing fluid is $120 \mathrm{MPa} \cdot \mathrm{s}$, and the grouting flow rate $(q)$ is $20 \mathrm{ml} / \mathrm{min}$. Due to the tensile strength of the G2 gravel consolidated interface, $\sigma_{\mathrm{t}}^{*}=7.4 \mathrm{MPa}$. According to reference [28], $K_{\mathrm{IC}}=1.07$ $\mathrm{MPa} \cdot \mathrm{m}^{1 / 2}$. More details about the experimental model can be found in reference [27].

4.4.2. Comparison and Analysis. Regardless of the yield shear force $\tau_{0}$ and the time-varying characteristics of the serous viscosity and the gravity effect of the fracture extension study, type (20) is adopted to determine how the grouting pressure changes with time; the calculation results are compared with the test results of sample \#2 [27] in Figure 4.

From Figure 4, we get to know the following three facts.

At the beginning of the test, the grouting pressure accumulates in the period of $0-240 \mathrm{~s}$. When the pressure increases to about $26.1 \mathrm{MPa}$, the hydraulic fracture in the rock sample initiates from inside the gravel. Since the gravel contact propagation mode of the hydraulic fractures is mainly dependent on the cementation condition of the interface and the tensile strength of the gravel body, the tensile strength of the G2 gravel cementation interface, which was measured using the Brazilian fracturing test, is $\sigma_{\mathrm{t}}^{*}=7.4 \mathrm{MPa}$. According to equation (1), the grouting pressure of the horizontal fractures formed in this experiment is $23.5 \mathrm{MPa}$. In comparison, there is a certain deviation between the calculated and measured values of the grouting pressure required for rock sample initiation. This is because there is a gravel belt with a large grain size in the axis direction of the vertical open hole in the middle of rock sample $\# 2$, and the tensile strength of the gravel body is greater than that of the cement surface.

During the test, fracturing behavior occurs from $240 \mathrm{~s}$ to $600 \mathrm{~s}$, so the starting time of the theoretical calculation was set as $240 \mathrm{~s}$, and the theoretical value of the grouting pressure in the fracture expansion process was calculated using equation (19), as shown in Figure 3. We found that the required grouting pressure is increasing and slope is constantly increasing with the continuation of grouting time by comparing calculated values with experimental values of grouting pressure. The theoretical calculated value is in good agreement with the experimental results for 240-600 s.

Later in the experiment, the rapid expansion of the fractures occurs along the fracture surface to the boundary of the rock samples, and the pumping pressure rapidly decreases to about $3 \mathrm{MPa}$ from $600 \mathrm{~s}$ to $800 \mathrm{~s}$.

\section{Analysis of the Main Factors Influencing Grouting in Deeply Buried Rock Strata}

Based on the above theoretical model, for $\alpha=60^{\circ}, \theta=120^{\circ}$, and $r=0.02 \mathrm{~m}$, we analyze the influence of the formation factors (strata depth), the time-varying characteristics of the serous viscosity, the grouting pressure, and the grouting flow rate on the fracture diffusion of the grout in deeply buried strata.

5.1. Depth of the Strata. For a final fracture diffusion radius of the slurry $L=2 \mathrm{~m}, b=0.002 \mathrm{~m}, K_{\mathrm{IC}}=0.25 \mathrm{MPa} \cdot \mathrm{m}^{1 / 2}$, and $q=2.5 \times 10^{-4} \mathrm{~m}^{3} / \mathrm{s}$, the slurry reference literature [17], and $\mathrm{C}: S=1: 1$ cement and sodium silicate slurry, $u(t)=$ $0.003182 t^{2.5}$ and $\tau_{0}=6 \mathrm{~Pa}$. According to equation (18), the $P_{0}$ value of the grouting pressure required for different strata depths and lateral pressure coefficients is calculated, as shown in Figure 5.

The analysis of Figure 5 shows that $P_{0}$ of the fracture grouting pressure is linearly proportional to the strata depth $H$ and the lateral pressure coefficient $k$. When the burial depth of the injected rock mass increases from $300 \mathrm{~m}$ to $400 \mathrm{~m}, k=1.0$, and the corresponding diffusion radius is $L=2.0 \mathrm{~m}$, the grouting pressure $P_{0}$ increases from $15.6 \mathrm{MPa}$ to $18.6 \mathrm{MPa}$. When the burial depth of the injected rock mass increases from $300 \mathrm{~m}$ and the lateral pressure coefficient $k$ increases from 1.0 to 2.0, the grouting pressure $P_{0}$ increases from 15.6 MPa to 20.4 MPa. Thus, as the burial depth and the lateral pressure coefficient of the injected rock mass increase, 


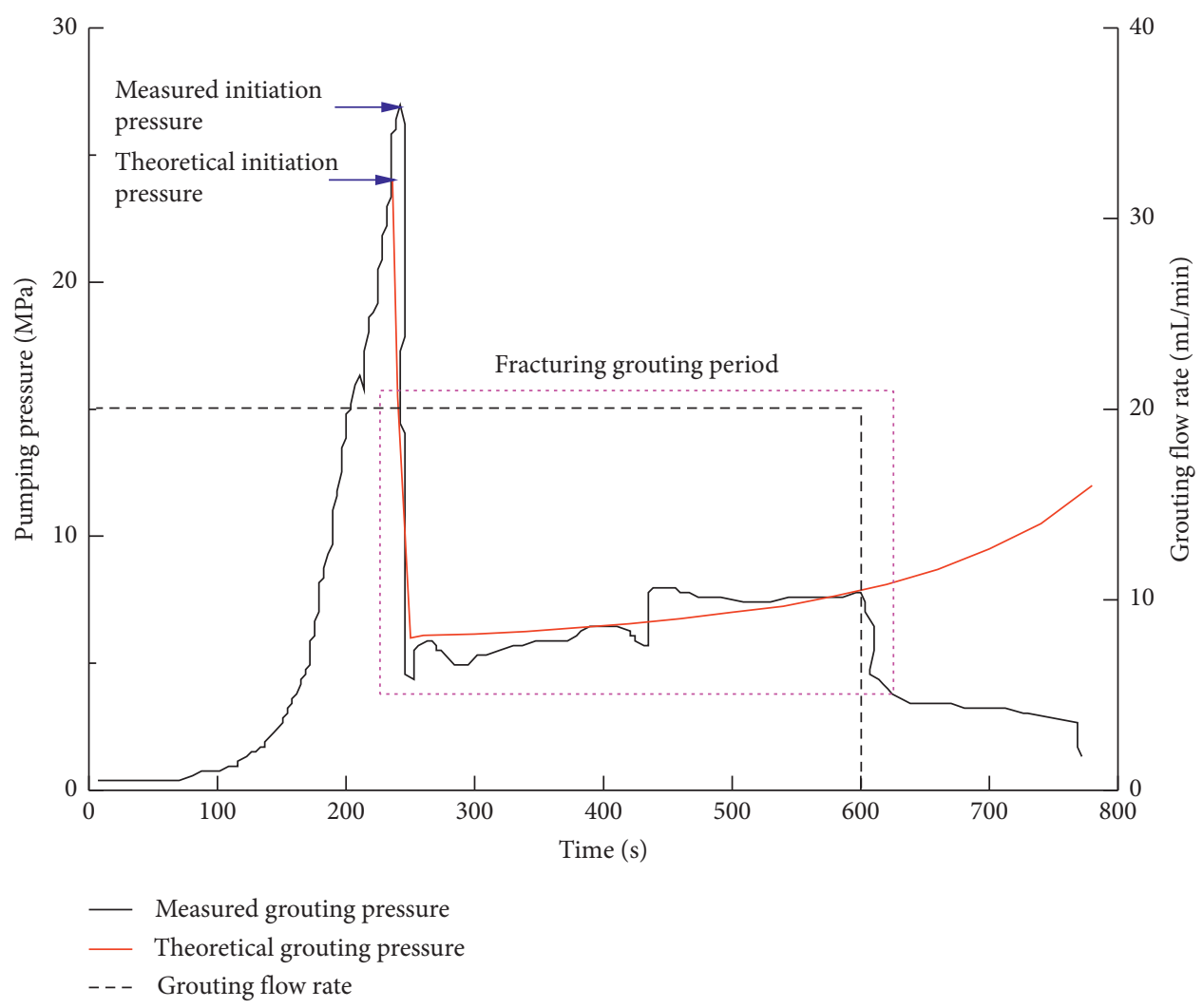

FIGURE 4: Grouting pressure versus time.

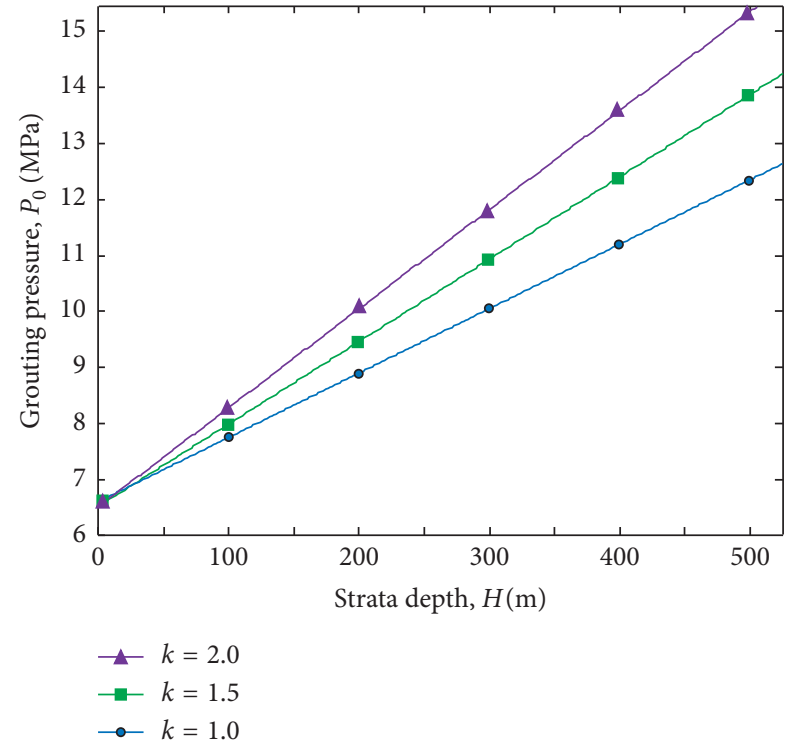

FIGURE 5: The influence of strata depth on the grouting pressure.

the fracturing diffusion resistance of the grout increases, and thus, the more difficult it is to expand the fracture. A greater grouting pressure $P_{0}$ is required to achieve the predetermined fracture diffusion radius.

5.2. Time-Varying Characteristics of the Serous Viscosity. The plot of the cement and sodium silicate slurry viscosity $u(t)$ versus time was fitted according to the relationship between the viscosity of the slurry and the sodium silicate slurry with time proposed in reference [19], as shown in Figure 6. When $\sigma_{\mathrm{cz}}=12 \mathrm{MPa}, P_{\mathrm{s}}=2 \mathrm{MPa}, k=1.5, b=0.002 \mathrm{~m}$, $K_{\mathrm{IC}}=0.25 \mathrm{MPa} \cdot \mathrm{m}^{1 / 2}$, and $q=2.5 \times 10^{-4} \mathrm{~m}^{3} / \mathrm{s}$, by combining equations (18) and (20), $P$ - $L$ curves with and without considering viscosity were drawn to analyze the influence of the time-varying characteristics of the serous viscosity on the fracture diffusion distance of the slurry, as shown in Figure 7.

As can be seen from Figures 6 and 7, the time-varying characteristics of the serous viscosity of the cement and sodium silicate slurry have an important influence on the fracture grouting pressure and the diffusion radius. When the diffusion radius of the wall fracture is about $1 \mathrm{~m}$, due to the short grouting time, the plastic viscosity of the grout mixtures composed of different proportions is almost zero, so the corresponding fracture grouting pressure is the same and small. After that, the plastic viscosity of the slurry gradually increases with time, and the grouting pressures required by the slurry mixtures composed of different proportions to reach the same fracturing diffusion radius are significantly different. For example, when the maximum fracturing diffusion distance is $L=3 \mathrm{~m}$, the grouting pressure required for $C: S$ values of $2: 1$ and $1: 1$ and a plastic viscosity of 0 is $45 \mathrm{MPa}, 35 \mathrm{MPa}$, and $19.5 \mathrm{MPa}$, respectively.

When selecting grouting parameters for project, the slurry proportions should be reasonably selected according to the grouting design requirements, and the influence of the time-varying characteristics of the serous viscosity on the grouting pressure and the slurry diffusion radius should be fully considered. 


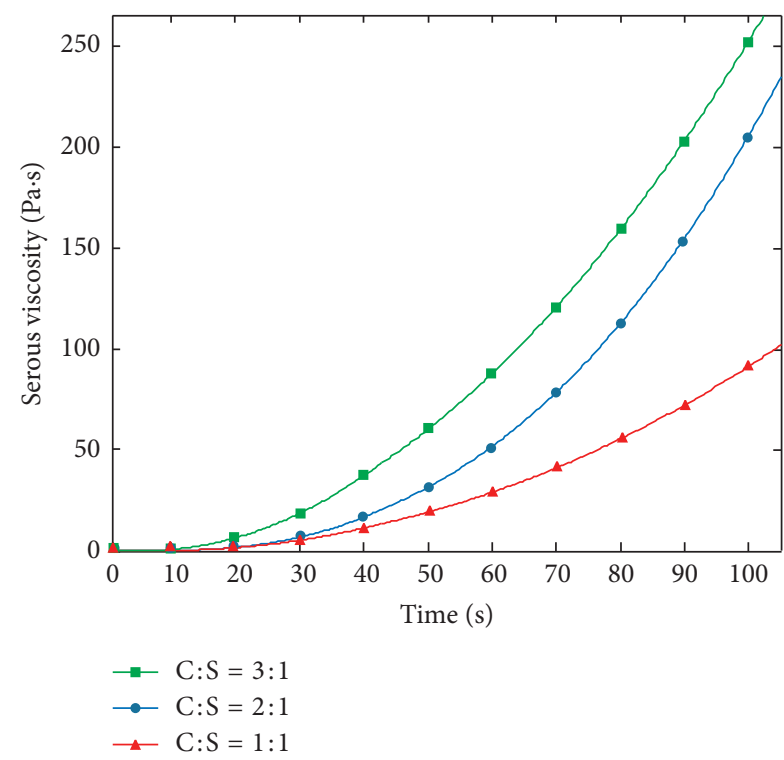

FIGURE 6: C-S slurry viscosity versus time.

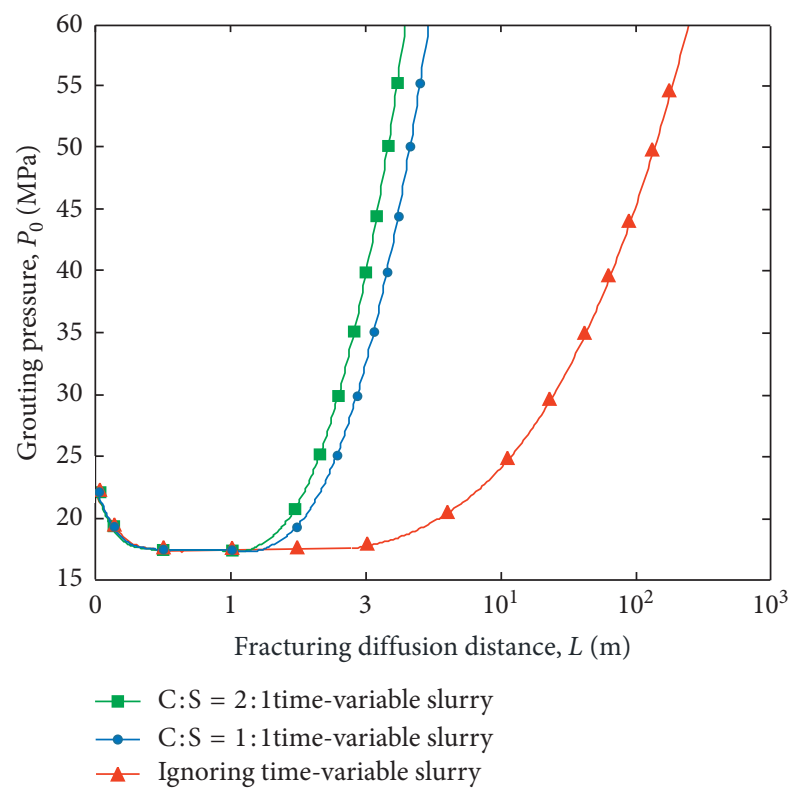

Figure 7: The influence of the viscosity-time denaturation on the slurry splitting diffusion distance.

5.3. Grouting Flow Rate. In order to analyze the influence of the grouting pressure and the grouting flow rate on the fracture diffusion distance, for $\sigma_{\mathrm{cz}}=12 \mathrm{MPa}, P_{\mathrm{s}}=2 \mathrm{MPa}$, $k=1.5, b=0.002 \mathrm{~m}, K_{\mathrm{IC}}=0.25 \mathrm{MPa} \cdot \mathrm{m}^{1 / 2}$, and a $\mathrm{C}: S=1: 1$ cement and sodium silicate slurry, $u(t)=0.003182 t^{2.5}$ and $\tau_{0}=6 \mathrm{~Pa}$. According to equation (18), the grouting pressure $P_{0}$ required for a corresponding fracture diffusion radius $L$ can be calculated for different grouting flow rates $q$, as shown in Figure 8.

As can be seen from Figure 8, the diffusion radius of the grouting in deeply buried rock strata is nonlinearly proportional to the grouting pressure and the grouting flow rate. In the initial stage of the grouting process, the pressure

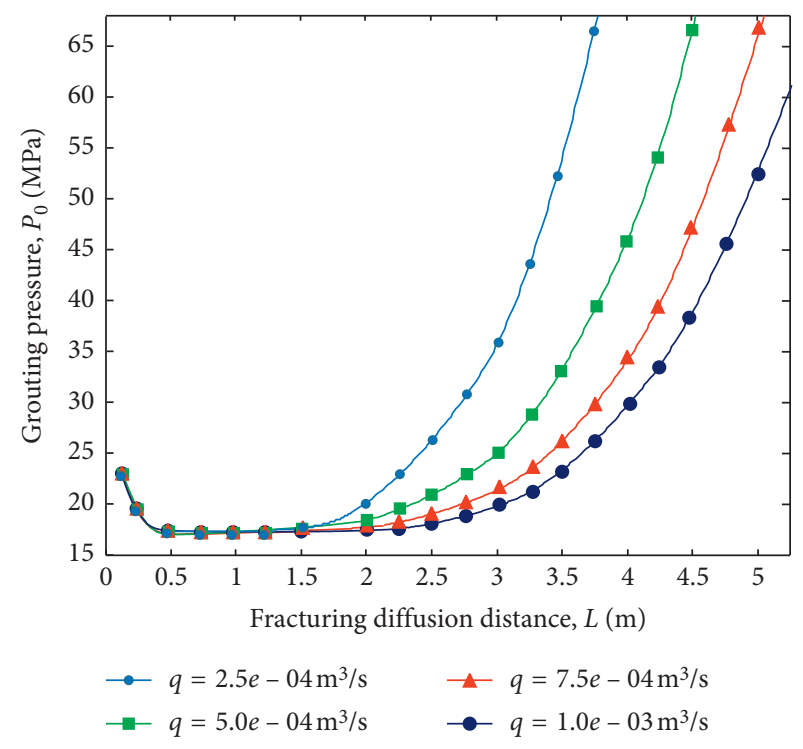

Figure 8: Influence of the grouting flow rate on the fracture diffusion distance.

required for fracture initiation is relatively large, and the grouting pressure required for fracture extension after fracture initiation is decreased. When the fracture expands to more than $1.5 \mathrm{~m}$, the grouting pressure required for further expansion of the fracture increases sharply. When the grouting fracture diffusion radius $L$ is small, the grouting flow rate $q$ has little influence on the grouting pressure $P_{0}$ required. However, when the diffusion radius $L$ of the fracture grouting is greater than $1.5 \mathrm{~m}$, the grouting flow rate $q$ has a significant impact on the required grouting pressure $P_{0}$. For example, when the diffusion radius of the grouting is $2.5 \mathrm{~m}$, the grouting pressure $P_{0}$ is $23 \mathrm{MPa}$ and $17 \mathrm{MPa}$ for grouting flow rates $q$ of $2.5 \times 10^{-4} \mathrm{~m}^{3} / \mathrm{s}$ and $1.0 \times 10^{-3} \mathrm{~m}^{3} / \mathrm{s}$, respectively, i.e., a difference of 0.35 times. When the diffusion radius of the grouting is $3.5 \mathrm{~m}$, the grouting pressure $P_{0}$ is $52 \mathrm{MPa}$ and $22 \mathrm{MPa}$ for grouting flow rates $q$ of $2.5 \times 10^{-4} \mathrm{~m}^{3} / \mathrm{s}$ and $1.0 \times 10^{-3} \mathrm{~m}^{3} / \mathrm{s}$, respectively, i.e., a difference of 1.36 times. Therefore, for deeply buried rock strata, the grouting pressure and the grouting flow rate should be increased simultaneously to effectively increase the grouting diffusion radius. In addition, it is difficult to achieve the expected grouting effect by simply increasing the grouting pressure.

Based on the above analysis, when a Bingham fluid slurry is involved in the fracturing and expansion in deeply buried rock strata with a rich water depth, the fracturing is controlled by the formation factors (strata depth), the timevarying characteristics of the serous viscosity, the grouting pressure, and the grouting flow rate. Calculating the sensitivity of each influence factor to the fracture diffusion distance [29], the sensitivity coefficients of strata depth, the time-varying characteristics of the serous viscosity, the grouting pressure, and the grouting flow rate are $0.011,65.7$, 0.432 , and 0.148 , respectively.

Therefore, the sensitivity coefficient is ranked from greatest to least as follows: time-varying characteristics of the 
time-varying characteristics of the serous viscosity $>$ grouting pressure $>$ grouting flow rate $>$ strata depth. The time-varying characteristics of the serous viscosity significantly influence $L$, and the time-varying characteristics of the viscosity can be controlled by reasonably selecting the slurry proportion parameters. In addition, the grouting pressure and the grouting flow rate can be flexibly adjusted to create slurry fractures and expand them within the ideal range.

\section{Conclusions}

(1) When the fracture tip stress intensity factor $K_{\mathrm{I}}$ is equal to the material fracture toughness $K_{\mathrm{IC}}$ discriminant conditions for fracturing, it is necessary to comprehensively consider the crustal stress characteristics of deeply buried rock strata, the mechanical properties of the rock, the time-varying characteristics of the serous viscosity, and various factors. We derived a fracture grouting diffusion equation and tested it. This deeply buried rock strata fracture grouting design provides a theoretical basis for engineering applications.

(2) The fracture grouting pressure $P_{0}$ is linearly proportional to the strata depth $H$ and the lateral pressure coefficient $k$. As the burial depth and the lateral pressure coefficient of the injected rock mass increase, the fracture diffusion resistance of the slurry increases, and a greater grouting pressure $P_{0}$ is required to reach the predetermined fracture diffusion radius.

(3) The time-varying characteristics of the serous viscosity of the grouting slurry have an important influence on the grouting pressure and diffusion radius. The early impact is small, and the later impact is large. In the selection of grouting parameters, the slurry proportions should be reasonably selected according to the grouting design requirements and the above influences.

(4) The diffusion radius of the grouting is nonlinearly proportional to the grouting pressure and the grouting flow rate. For deeply buried strata, the grouting pressure and grouting flow rate should be increased simultaneously to effectively increase the grouting diffusion radius. It is difficult to achieve the expected grouting effect simply by increasing the grouting pressure.

(5) According to the sensitivity analysis of the main factors affecting the diffusion radius of the grout, the sensitivity coefficients of the strata depth, the grouting pressure, the time-varying characteristics of the serous viscosity, and the grouting flow rate are ordered from least to greatest as follows: timevarying characteristics of the serous viscosity $>$ grouting pressure $>$ grouting flow rate $>$ strata depth.

\section{Data Availability}

The data used to support the findings of this study are included within the article.

\section{Conflicts of Interest}

The authors declare that there are no conflicts of interest regarding the publication of this paper.

\section{Acknowledgments}

This study was supported by the National Key Research and Development program (2016YFC0600902) and the National Natural Science Foundation of China (51874005).

\section{References}

[1] H. Cheng, Theory and Technology of Freezing in Deep Alluvium, Science and Technology Press, Beijing, China, 2016.

[2] Q.-L. Liu and H. Cheng, "Study on grouting reinforcement mechanism and grouting parameters of post-walled soil," Journal of Coal Science, vol. 25, no. 5, pp. 486-490, 2000.

[3] M. He, H. Xie, S. Peng et al., "Research on deep mining rock mass mechanics," Chinese Journal of Rock Mechanics and Engineering, vol. 24, no. 16, pp. 2803-2813, 2005.

[4] G. Gustafson, J. Claesson, and A. Fransson, "Steering parameters for rock grouting," Journal of Applied Mathematics, vol. 2013, Article ID 269594, 9 pages, 2013.

[5] A. C. Houlsby, Construction and Design of Cement Grouting: A Guide to Grouting in Rock Foundations, Wiley, Hoboken, NJ, USA, 1990.

[6] G. Lombardi, "The role of cohesion in cement grouting of rock," in Proceedings of the 15th Congress on Large Dams 1985, pp. 235-261, ICOLD, Paris, France, 1985.

[7] C. Baker, Comments on Paper Rock Stabilization in Rock Mechanics. Muler, Springer-Verlag, New York, NY, USA, 1974.

[8] T.-L. Chen, L.-Y. Zhang, and D.-L. Zhang, "An FEM/VOF hybrid formulation for fracture grouting modelling," Computers and Geotechnics, vol. 58, pp. 14-27, 2014.

[9] L. Zou, V. U. Håkansson, and V. Cvetkovic, "Two-phase cement grout propagation in homogeneous water-saturated rock fractures," International Journal of Rock Mechanics and Mining Sciences, vol. 106, pp. 243-249, 2018.

[10] W. Wittlke, New Technology for Grouting with Thick Paste of Thick Paste. Modern Irrigation Technology Translation, pp. 48-58, Water Conservancy and Electric Power Press, Beijing, China, 1991.

[11] J. F. Zou, L. Li, and X. L. Yang, "Analysis of diffusion radius and pressure attenuation of split grouting," Chinese Journal of Hydraulic Engineering, vol. 37, no. 3, pp. 0314-0319, 2006.

[12] F. Sun, T. Chen, D. Zhang et al., "Study on the splitting grouting mechanism of submarine tunnel based on bingham mass grout," Journal of Beijing Jiaotong University, vol. 33, no. 4, pp. 1-6, 2009.

[13] F. Sun, D. Zhang, and T. Chen, "Study on the mechanism of tunnel splitting grouting based on fluid time-varyin," Journal of Geotechnical Engineering, vol. 33, no. 1, pp. 88-93, 2011.

[14] Z.-M. Zhang and J. Zou, "Study on diffusion radius and grouting pressure of splitting grouting at pile bottom," Journal of Geotechnical Engineering, vol. 30, no. 2, pp. 181-184, 2008.

[15] M. Zhang, X. Wang, and Y. Wang, "Study on diffusion law of Herschel-Bulkley slurry in cracks," Journal of Geotechnical Engineering, vol. 33, no. 5, p. 815, 2011.

[16] L. I. Shu-cai, W.-J. Zhang, Q.-S. Zhang et al., "Research on advantage-fracture grouting mechanism and controlled grouting method in water-rich fault zone," Rock and Soil Mechanics, vol. 35, no. 3, pp. 745-751, 2014. 
[17] W. Zhang, S. Li, J. Wei et al., Grouting Rock Fractures with Cement and Sodium Silicate Grout, Carbonates and Evaporites, USA, 2017.

[18] S. Z. Zheng, Y. Xiao, L. Rentai et al., "Transient analysis of grout penetration with time-dependent viscosity inside 3D fractured rock mass by unified pipe-network method," Water, vol. 10, no. 9, pp. 1122-1140, 2018.

[19] R. Liu, Study on Mechanism and Application of Water-Jet Grouting Diffusion Sealing in Cement-Based Quick-Setting Slurry Underground Engineering, Shandong University, Jinan, China, 2012.

[20] S. Yi and Z. zhu, Introduction to Fracture Rock Mass Damage Mechanics, pp. 87-90, Science Press, Beijing, China, 2005.

[21] H. Wang, Principles of Hydraulic Fracturing, Petroleum industry press, Beijing, China, 1987.

[22] J. Wu and $\mathrm{M}$. Wu, "Experimental study on rock fracture under triaxial compression with inner hole," Seismology, vol. 8, no. 2, pp. 69-76, 1986.

[23] A. A. Savitski and E. Detournay, "Propagation of a pennyshaped fluid-driven fracture in an impermeable rock: asymptotic solutions," International Journal of Solids and Structures, vol. 39, no. 26, pp. 6311-6337, 2002.

[24] J. R. Rice, "Mathematical analysis in the mechanics of fracture," in Fracture, an Advanced Treatise (Chapter 3), H. Liebowitz, Ed., vol. 2, pp. 191-311, Academic Press, New York, NY, USA, 1968.

[25] S. Mohajerani, R. A. Baghbanan, and H. Hashemolhosseini, "Grout penetration in fractured rock mass using a new developed explicit algorithm," International Journal of Rock Mechanics and Mining Sciences, vol. 80, pp. 412-417, 2015.

[26] Q. Zhang, L. zhang, R. Liu et al., "Study on the theory of split grouting based on the stress coupling effect of "slurry soil" interface," Chinese Journal of Geotechnical Engineering, vol. 38, no. 2, pp. 323-330, 2016.

[27] L. Ning, S. Zhang, X. Ma et al., "Experimental study on hydrofracture propagation rule of conglomerate reservoir," Journal of Rock Mechanics and Engineering, vol. 36, no. 10, pp. 47-56, 2017.

[28] Z. X. Zhang, "An empirical relation between mode I fracture toughness and the tensile strength of rock," International Journal of Rock Mechanics and Mining Sciences, vol. 39, no. 3, pp. 401-406, 2002.

[29] W. Gong, P. Wang, and F. Chen, "Sensitivity analysis of slope stability in bedding rock cutting," Rock and Soil Mechanics, vol. 28 , no. $4,2007$. 


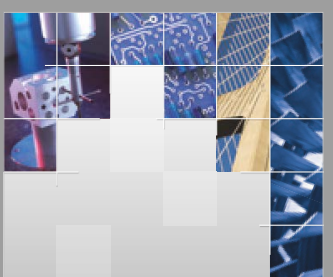

\section{Enfincering}
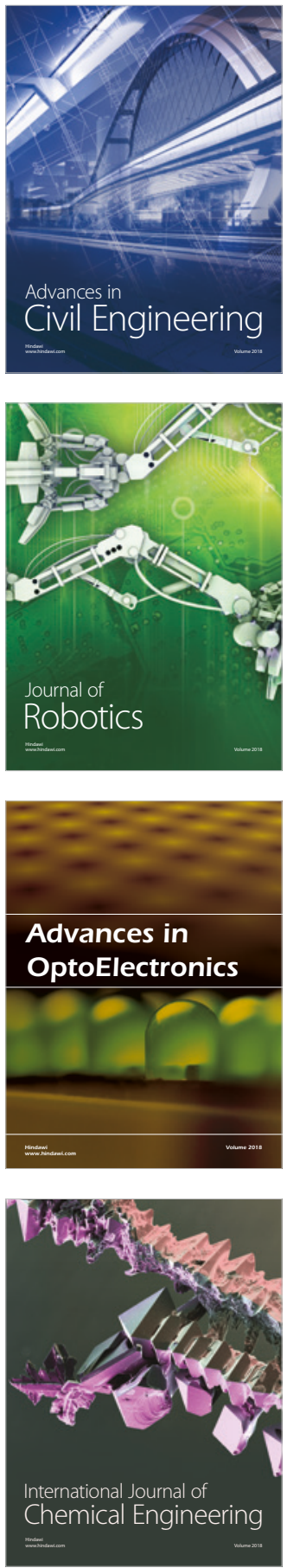

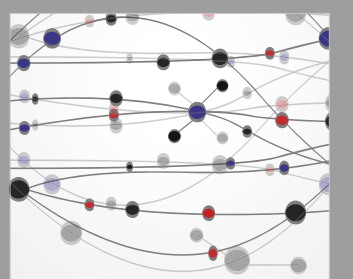

\section{Rotating \\ Machinery}

The Scientific World Journal



Submit your manuscripts at

www.hindawi.com
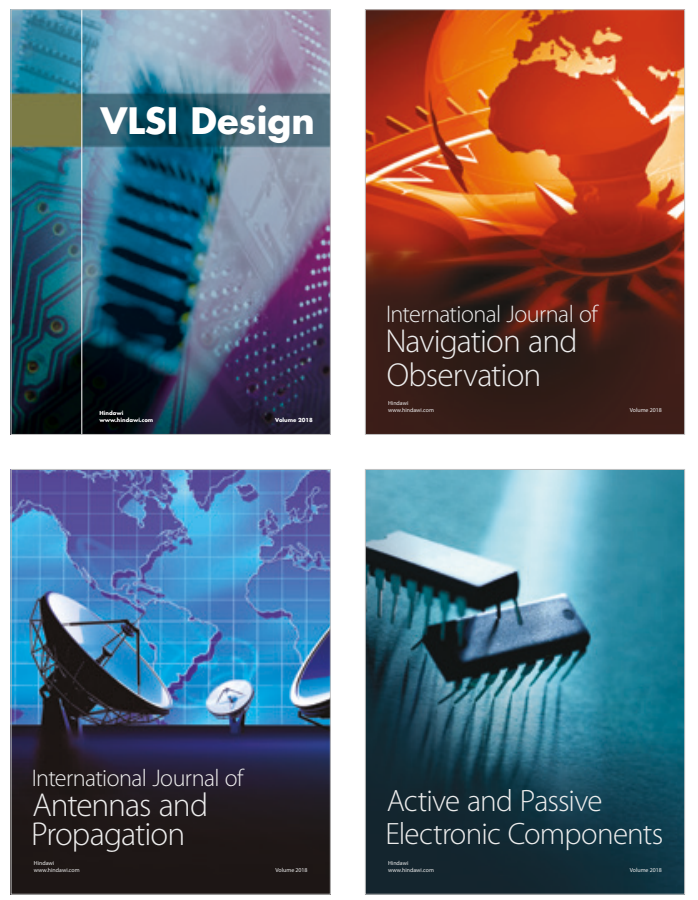
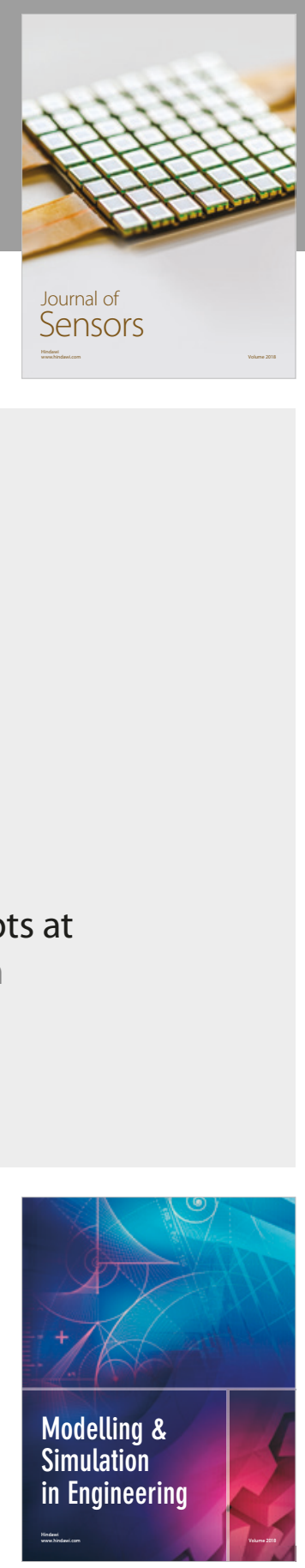

\section{Advances \\ Multimedia}
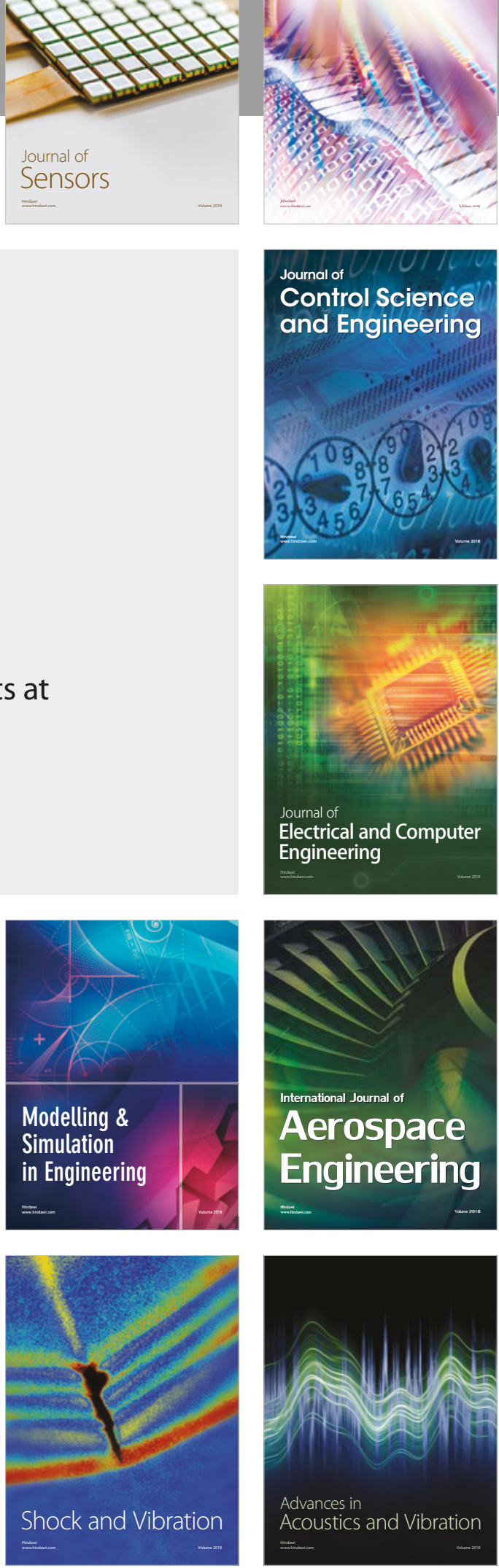